\title{
Extensive endarterectomy and reconstruction of the left anterior descending artery: Early and late outcomes
}

\author{
Patrick O. Myers, MD, Minoru Tabata, MD, MPH, Prem S. Shekar, MD, Gregory S. Couper, MD, \\ Zain I. Khalpey, MD, PhD, and Sary F. Aranki, MD
}

Objectives: Coronary endarterectomy has been shown to be an effective adjunctive technique of revascularization for diffuse coronary artery disease. A long arteriotomy and reconstruction of the left anterior descending artery (LAD) are occasionally required for complete extraction of the atherosclerotic plaque. The aim of this study was to examine early and late results of this technique and compare 2 different reconstruction methods.

\begin{abstract}
Methods: We retrospectively reviewed 224 consecutive patients who underwent extensive LAD endarterectomy and reconstruction between January 1992 and March 2010. For reconstruction, 101 patients underwent saphenous vein patch and LAD grafting (group A) and 123 patients had left internal thoracic artery onlay patch grafting (group B). We compared early and late outcomes and assessed the association of the reconstruction method and long-term survival.
\end{abstract}

Results: The mean age was 66 and 67 years in groups A and B, respectively. Operative mortality was $3.0 \%$ and $4.1 \%$, and the incidence of perioperative myocardial infarction in the LAD territory was $4.0 \%$ and $4.1 \%$ in groups $\mathrm{A}$ and $\mathrm{B}$, respectively. There was no significant difference in early operative outcomes $(P>.05)$. Actuarial 5-year survival was $78.6 \%$ and $87.1 \%$ and 10 -year survival was $45.4 \%$ and $49.4 \%$ in groups $\mathrm{A}$ and $\mathrm{B}$, respectively. Cox hazard proportional analysis showed that the reconstruction method did not have a significant impact on long-term survival.

Conclusions: Extensive LAD endarterectomy and reconstruction is a safe and feasible technique of revascularization for diffuse coronary artery disease. The reconstruction method should be based on the availability of conduits and length of the arteriotomy. (J Thorac Cardiovasc Surg 2012;143:1336-40)

An increasing number of patients with advanced coronary artery disease and diffusely complex atherosclerotic lesions are referred for coronary artery bypass grafting (CABG). Coronary endarterectomy has been shown to be a feasible and safe technique for diffusely diseased coronary arteries in several recent studies, although it was initially associated with an increased operative morbidity and mortality. ${ }^{1-7}$ More recently, left anterior descending artery (LAD) endarterectomy has been shown to be safer than previously thought. ${ }^{8-11}$ Unlike the right coronary artery, the $\mathrm{LAD}$ atherosclerotic core is narrow and delicate, which increases the risk of disruption under tension. Furthermore, the LAD has diagonal and septal branches that occur in 2 different planes. As a result, unidirectional traction on the plaque can cause shearing off of branches. ${ }^{12}$ At the same time, the LAD warrants endarterectomy for the purpose of complete revascularization of those

From the Division of Cardiac Surgery, Brigham and Women's Hospital and Harvard Medical School, Boston, Mass.

Disclosures: Authors have nothing to disclose with regard to commercial support.

Received for publication July 2, 2011; revisions received Aug 8, 2011; accepted for publication Aug 25, 2011; available ahead of print April 16, 2012.

Address for reprints: Sary F. Aranki, MD, Division of Cardiac Surgery, Brigham and Women's Hospital and Harvard Medical School, 75 Francis St, Boston, MA 02115 (E-mail: saranki@partners.org).

0022-5223/\$36.00

Copyright (C) 2012 by The American Association for Thoracic Surgery doi: $10.1016 /$ j.jtcvs.2011.08.058 important branches. Open coronary endarterectomy, involving a long arteriotomy, is necessary when plaque extraction is incomplete through a limited arteriotomy from undue resistance or when the plaque is fractured. The open technique under these circumstances provides adequate exposure to extract the atherosclerotic core. The basic principle of coronary endarterectomy is complete extraction of the plaque. Nishi and associates ${ }^{13}$ showed that the midterm angiographic results of open coronary endarterectomy with onlay patch grafting are better than those of the traction technique.

There are different strategies to reconstruct the LAD after extensive endarterectomy. Because of the prevalence of thrombosis, primary closure techniques have been abandoned. Saphenous vein grafting is used occasionally; however, the technique demonstrated poorer outcomes than left internal thoracic artery (LITA) grafting. ${ }^{14}$ Open LAD endarterectomy with saphenous vein patch reconstruction combined with LITA grafting was first reported by Fundaro and associates ${ }^{15}$ in 1987, with subsequent technical modifications introduced. ${ }^{16,17}$ LITA onlay patch grafting was established by Shapira and associates ${ }^{12}$ in 1988. Tasdemir and colleagues ${ }^{18}$ suggested that the low incidence of atherosclerotic disease of the LITA conduit is advantageous for this technique. More recently, Barra and coworkers ${ }^{19}$ described an endarterectomized LAD reconstruction technique with plaque exclusion using the LITA onlay patch graft, which 


\section{Abbreviations and Acronyms}

$\mathrm{CABG}=$ coronary artery bypass grafting

LAD $=$ left anterior descending artery

LITA $=$ left internal thoracic artery

PMI = perioperative myocardial infarction

replaces $75 \%$ of the circumference of the endarterectomized arterial wall with the LITA patch. Our group ${ }^{11}$ previously reported our midterm experience in LAD endarterectomy, which included all LAD endarterectomies.

In this study, we reviewed our results over an 18-year experience in the most severe disease, requiring open extensive endarterectomy and reconstruction of the LAD, and compared the outcomes of 2 different reconstruction methods.

\section{PATIENTS AND METHODS \\ Study Design and Patient Data}

This retrospective cohort study was conducted between January 1992 and March 2010, during which time 14,941 consecutive patients underwent CABG to the LAD at our institution. Of these patients, 639 (4.3\%) underwent $\mathrm{LAD}$ endarterectomy in addition to CABG. Of them, 224 patients underwent extensive LAD endarterectomy with a long arteriotomy and reconstruction of the $\mathrm{LAD}$, which accounts for $1.5 \%$ of the total CABG to the LAD. One hundred one patients had saphenous vein patch combined with LITA grafting (group A) and 123 patients had LITA onlay patch grafting (group B).

All preoperative, in-hospital, and postdischarge data were collected from the medical records and the Brigham and Women's Hospital cardiac surgery database according to definitions from The Society of Thoracic Surgeons adult cardiac database version 2.52. Recent myocardial infarction was defined as a myocardial infarction that occurred 1 to 7 days before surgery. Old myocardial infarction was defined as a myocardial infarction that occurred more than 7 days before surgery. Perioperative myocardial infarction (PMI) was defined as new electrocardiographic or echocardiographic changes with creatine kinase MB more than $100 \mathrm{ng} / \mathrm{mL}$.

Long-term survival data were collected from the national Social Security Number Database. This study was approved by the Institutional Review Board of Brigham and Women's Hospital and individual patient consent was waived.

\section{Indications for LAD Endarterectomy}

In practice, we perform endarterectomy for a diffusely diseased coronary artery in which we cannot pass a 1-mm probe. Importantly, this approach is not always predictable. We occasionally find that coronary arteries cannot be revascularized with a plain CABG procedure after making an arteriotomy, contrary to preoperative angiographic findings. In such cases, there is no other option than endarterectomy. In principle, we do not perform endarterectomy for nonviable myocardium, although viability studies were not performed systematically in the preoperative workup. We consider endarterectomy unless we are certain about nonviability.

\section{Surgical Procedure}

All procedures were performed with median sternotomy and cardiopulmonary bypass. Deep hypothermic circulatory arrest was required in only 1 patient, for proximal anastomosis on a calcified ascending aorta.
After the coronary arteriotomy, an endarterectomy spatula was used to identify the plane of dissection and then to mobilize the plaque proximally and distally. A 1-mm probe was advanced gently through the plane of dissection to break away resistant adhesions. A combination of gentle traction on the plaque and countertraction on the adventitia is useful to extract the plaque. When proper distal tapering of the specimen was not achieved, the arteriotomy was extended distally for complete extraction of the plaque. The proximal end of the endarterectomy should be distal to the most proximal lesion, to avoid competitive flow through the native coronary artery, to the level of the first diagonal branch at most. The length of endarterectomy did not vary between groups of LAD reconstruction techniques: it had to be considered complete in both groups. The atherosclerotic plaque varies from soft to extremely calcified and adherent. This characteristic dictates the length of the arteriotomy inasmuch as adherent plaques cannot be removed easily through a limited arteriotomy to at least the distal two thirds of the length of the LAD. If this was the case, the arteriotomy was extended to allow for complete extraction of the atherosclerotic core.

After complete extraction, retrograde cardioplegic solution was given to flush out any debris that may have embolized distally. A visible flow of retrograde cardioplegic solution through the diagonal and septal branches is indicative of successful endarterectomy.

The saphenous vein patch was applied to the endarterectomized LAD with a long arteriotomy and the LITA was then applied to either the middle of the vein patch or the proximal end of the LAD arteriotomy (Figure 1). LITA onlay patch grafting was used for a relatively short arteriotomy after confirming that there was no tension on the graft.

\section{Postoperative Management}

Continuous intravenous unfractionated heparin $(500 \mathrm{units} / \mathrm{h})$ was initiated after chest tube output dropped below $50 \mathrm{~mL}$ for 2 consecutive hours and was continued for 24 hours. Aspirin was started on the day of the operation. Before 1999, warfarin was administered for at least 3 months after the operation. Since 1999, clopidogrel has been used for 1 year after the operation instead of warfarin.

\section{Statistical Analysis}

The continuous variables are expressed with mean \pm standard deviation or median if the variables were not normally distributed. For comparison of the 2 groups, an unpaired $t$ test, Wilcoxon rank sum test, or Fisher's exact test was used as deemed appropriate. The Kaplan-Meier method and Breslow test were used to analyze long-term survival. Cox hazard proportional models were constructed to assess the adjusted association between the LAD reconstruction method and long-term survival. Stepwise selection was used for selecting the covariates in the model. All statistical tests were 2-tailed. Statistical analyses were performed using SPSS version 18 (SPSS, Inc, Chicago, Ill).

\section{RESULTS \\ Preoperative Characteristics}

The mean age of the entire study population was $66.2 \pm$ 10.2 years, $84 \%$ of whom were male. None of the patients had an acute myocardial infarction within 24 hours before the operation. The preoperative characteristics of each group are shown in Table 1 .

\section{Intraoperative Data}

The mean number of grafts was $3.2 \pm 0.8$ and $3.3 \pm 0.9$ in groups $\mathrm{A}$ and $\mathrm{B}$, respectively $(P=.206)$. The cardiopulmonary bypass times were $174 \pm 59$ and $138 \pm 50$ minutes $(P<.001)$ and the aortic crossclamp times were $131 \pm 49$ 


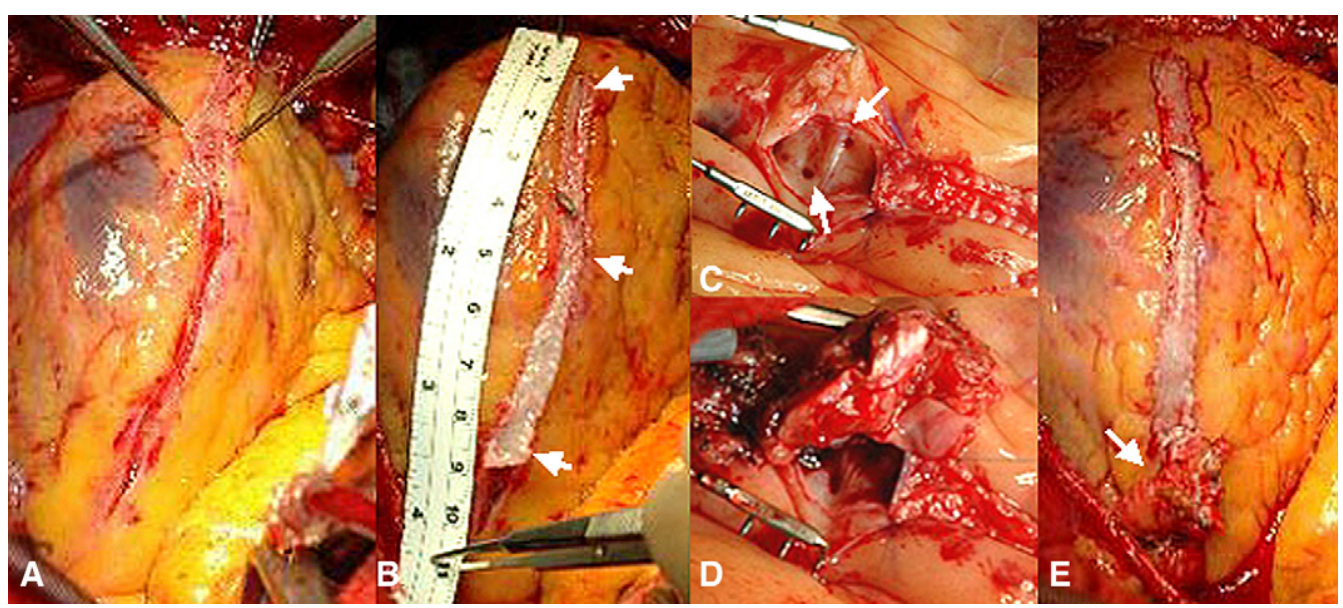

FIGURE 1. A, Extensively endarterectomized left anterior descending artery with a long arteriotomy. B, Long saphenous vein patch (arrows) is applied to the distal portion of the left anterior descending artery (LAD). C, Remaining arteriotomy of the LAD after vein patch application. (Arrows mark diagonal and septal branches). D, Excellent returning flow of retrograde cardioplegic solution from the endarterectomized vessel. E, Left internal thoracic artery graft (arrow) is applied to the proximal portion of LAD with edge-to-edge sutures with a vein patch.

and $109 \pm 44$ minutes $(P=.001)$ in groups $\mathrm{A}$ and $\mathrm{B}$, respectively.

In group A, $3(3.0 \%)$ patients underwent concomitant mitral valve repair, $3(3.0 \%)$ had concomitant transmyocardial laser revascularization, $2(2.0 \%)$ had mitral valve repair and left ventricular aneurysm repair, $1(1.4 \%)$ had aortic valve replacement and mitral valve replacement, 1

TABLE 1. Preoperative characteristics

\begin{tabular}{|c|c|c|c|}
\hline Variables & $\begin{array}{c}\text { Group A } \\
(\mathbf{n}=101): \\
\text { SVG patch }\end{array}$ & $\begin{array}{c}\text { Group B } \\
(n=123): \\
\text { LITA onlay }\end{array}$ & $\begin{array}{c}P \\
\text { value }\end{array}$ \\
\hline Mean age (y) & $65.8 \pm 10.5$ & $66.6 \pm 9.9$ & $.56^{*}$ \\
\hline Male & $79(78.2 \%)$ & $110(89.4 \%)$ & $.03 \dagger$ \\
\hline Recent MI (1-7 d preop) & $18(17.8 \%)$ & $18(14.6 \%)$ & $.59 \dagger$ \\
\hline Old MI (>7 d preop) & $59(58.4 \%)$ & $61(49.6 \%)$ & $.23 \dagger$ \\
\hline Left main disease & $15(14.9 \%)$ & $27(22.0 \%)$ & $.23 \dagger$ \\
\hline Triple vessel disease & $86(85.1 \%)$ & $110(89.4 \%)$ & $.42 \dagger$ \\
\hline Preop IABP & $12(11.9 \%)$ & $8(6.5 \%)$ & $.24 \dagger$ \\
\hline Ejection fraction $<40 \%$ & $27(26.7 \%)$ & $27(21.9 \%)$ & $.53 \dagger$ \\
\hline NYHA class $\geq 3$ & $33(32.7 \%)$ & $45(36.6 \%)$ & $.58 \dagger$ \\
\hline Diabetes mellitus & $50(49.5 \%)$ & $63(51.2 \%)$ & $.89 \dagger$ \\
\hline $\begin{array}{l}\text { Previous cerebrovascular } \\
\text { disease }\end{array}$ & $10(9.9 \%)$ & $19(15.4 \%)$ & $.24 \dagger$ \\
\hline Renal insufficiency & $10(9.9 \%)$ & $11(8.9 \%)$ & $.82 \dagger$ \\
\hline COPD & $29(28.7 \%)$ & $61(49.6 \%)$ & $.002 \dagger$ \\
\hline PVD & $19(18.8 \%)$ & $26(21.1 \%)$ & $.74 \dagger$ \\
\hline Previous cardiac surgery & $11(10.9 \%)$ & $4(3.3 \%)$ & $.03 \dagger$ \\
\hline Previous CABG & $9(8.9 \%)$ & $3(2.4 \%)$ & $.04 \dagger$ \\
\hline Previous PCI & $12(11.9 \%)$ & $27(22 \%)$ & $.05 \dagger$ \\
\hline Nonelective operation & $54(53.5 \%)$ & $60(48.8 \%)$ & $.50 \dagger$ \\
\hline
\end{tabular}

$S V G$, Saphenous vein graft; $L I T A$, left internal thoracic artery; $M I$, myocardial infarction; IABP, intra-aortic balloon pump; NYHA, New York Heart Association; COPD, chronic obstructive pulmonary disease; $P V D$, peripheral vascular disease; $C A B G$, coronary artery bypass grafting; $P C I$, percutaneous coronary intervention. *Independent sample $t$ test. †Fisher's exact test.
$(1.4 \%)$ had aortic valve repair, and $1(1.4 \%)$ patient had carotid endarterectomy. In group B, $3(2.4 \%)$ patients underwent concomitant aortic valve replacement, $1(0.8 \%)$ underwent mitral valve replacement, and $1(0.8 \%)$ patient underwent aortic valve replacement and mitral valve repair.

\section{Early Outcomes}

The operative mortality of the entire study population was $3.6 \%$ (8/224). Early operative outcomes of each group are shown in Table 2. In group A, $3(3.0 \%)$ patients required reoperation for bleeding, 1 from a prior saphenous vein graft and 2 from the chest wall. Eight (7.9\%) patients had PMI. Four $(4.0 \%)$ patients had anterior PMI. None of them required percutaneous coronary intervention or reoperation, although 1 required intra-aortic balloon pump placement after PMI. In group B, $2(1.6 \%)$ patients underwent reoperation for bleeding, 1 from the LAD anastomosis site and 1 from epicardial exploration of a posterior left ventricular branch. Eight $(6.5 \%)$ patients had PMI, $5(4.1 \%)$ of whom had PMI in the anterior wall, but they did not require percutaneous coronary intervention, reoperation, or intraaortic balloon pump insertion. There was no significant difference in early operative outcomes between the 2 groups. There was also no significant difference in early operative outcomes between patients managed with postoperative warfarin (before 1999) or clopidogrel (since 1999; data not presented).

\section{Late Outcomes}

The median follow-up interval was 58 months (range, 1-191 months). The actuarial survival was $83.1 \% \pm 2.7 \%$ at 5 years and $47.5 \% \pm 6.1 \%$ at 10 years for all 224 patients. In group A, 5- and 10-year actuarial survival outcomes were $78.6 \% \pm 4.3 \%$ and $45 \% .4 \pm 7.6 \%$, 
TABLE 2. Operative and early postoperative data

\begin{tabular}{|c|c|c|c|}
\hline Variables & $\begin{array}{c}\text { Group A } \\
(\mathrm{n}=101): \\
\text { SVG patch }\end{array}$ & $\begin{array}{c}\text { Group B } \\
(n=123): \\
\text { LITA onlay }\end{array}$ & $\begin{array}{c}P \\
\text { value }\end{array}$ \\
\hline Operative mortality & $3(3.0 \%)$ & $5(4.1 \%)$ & $.73 *$ \\
\hline Reoperation for bleeding & $3(3.0 \%)$ & $2(1.6 \%)$ & $.66^{*}$ \\
\hline PMI & $8(7.9 \%)$ & $8(6.5 \%)$ & $.79 *$ \\
\hline PMI of LAD territory & $4(4.0 \%)$ & $5(4.1 \%)$ & $1.00 *$ \\
\hline Intraop/postop IABP & $6(5.9 \%)$ & $4(3.3 \%)$ & $.35 *$ \\
\hline
\end{tabular}

SVG, Saphenous vein graft; LITA, left internal thoracic artery; PMI, perioperative myocardial infarction; $L A D$, left anterior descending artery; $I A B P$, intra-aortic balloon pump. *Fisher's exact test.

respectively. In group B, the 5- and 10-year actuarial survival result was $87.1 \% \pm 3.5 \%$ and $49.4 \% \pm 9.8 \%$, respectively (Figure 2). The difference between groups did not reach statistical significance $(P=.18)$. In Cox hazard proportional analyses, saphenous vein patch reconstruction demonstrated a trend toward increased long-term mortality, but not to a significant level (hazard ratio, $2.4 ; 95 \%$ confidence interval, $0.19-30.8 ; P=.50)$. In univariable Cox analysis, the anticoagulation vs antiaggregant protocol, as categorized by study period (before 1999 or since 1999), did not significantly affect late mortality (hazard ratio, 0.83 for anticoagulation group; $P=.55$ ).

\section{DISCUSSION}

$\mathrm{We}^{11}$ previously reported our results in 196 patients who underwent LAD endarterectomy between 1992 and 2000.

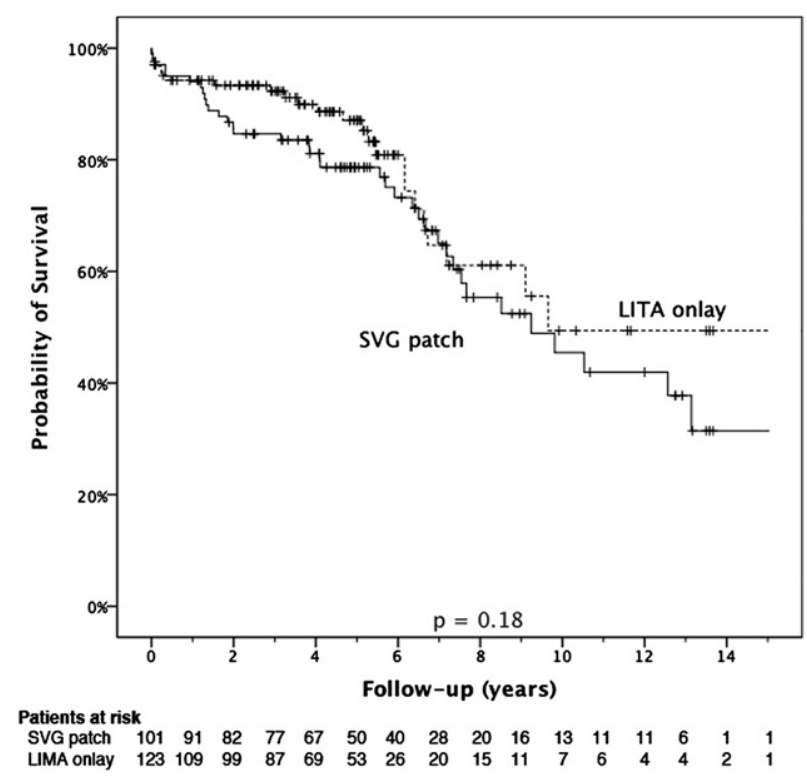

FIGURE 2. Kaplan-Meier survival curves for groups A (saphenous vein graft $[S V G]$ patch and left internal thoracic artery [LITA] graft reconstruction) and B (LIMA onlay reconstruction). There was no significant difference between the 2 curves (log rank test, $P=.18$ ).
Overall hospital mortality was $3 \%$ and the incidence of PMI in the LAD territory was also $3 \%$. Actuarial survival at 5 years was $75 \%$. In the current study, we analyzed a patient subgroup who had more pronounced disease that required extensive LAD endarterectomy and complex reconstruction with a saphenous vein or LITA onlay patch. This is the largest series of extended endarterectomy and reconstruction of the LAD reported to this date. Early and late outcomes were excellent and comparable with those of regular LAD endarterectomy despite the higher complexity of the procedure. These early results are also comparable with those of simple CABG, with a reported operative mortality of $2.3 \%$ for isolated $\mathrm{CABG}$ in The Society of Thoracic Surgeons national database, ${ }^{20}$ although midterm and long-term survivals are worse than those reported in simple CABG (eg, 5- and 10-year survivals of $92 \%$ and $78 \%$, respectively, in a report from the group at Emory University ${ }^{21}$ ). Overall, these results are favorable considering that these patients had severe and diffuse coronary artery disease for which simple CABG procedures would not have applied.

This study also shows that there was no significant difference in early and late operative outcomes between 2 different reconstruction methods. Crossclamp and cardiopulmonary bypass times were significantly longer in group A, perhaps owing to more extensive reconstruction of the LAD required for the long arteriotomy. However, improvements in myocardial protection have made crossclamp time a much less important factor in postoperative myocardial dysfunction. There was a trend toward increased late mortality ( $78 \%$ in group A vs $87 \%$ in group B at 5 years), which did not reach statistical significance. This is perhaps due to the fact that these 2 groups represent different anatomy or burden of atherosclerotic disease, inasmuch as the disease could be addressed through a small arteriotomy in group $\mathrm{B}$ and required a long, extensive arteriotomy to achieve the same technical result of endarterectomy in group A.

Implementing meticulous endarterectomy technique, providing adequate myocardial protection, and conducting postoperative antithrombotic management are as important as the reconstruction itself. Applying a meticulous endarterectomy technique is the most important aspect in reducing the risk of perioperative complications. Complete extraction of the atherosclerotic plaque is an essential prerequisite in this process. The worst outcome possible is usually associated with incomplete endarterectomy. Any residual intimal flaps should be removed carefully to prevent obstruction of the tributary vessels.

As much as optimal myocardial protection is essential for a successful procedure, we believe that the use of retrograde cardioplegia has a major impact on the results of coronary endarterectomy. Not only does it provide adequate myocardial protection, it also mechanically flushes and clears any debris that may have embolized distally. 
Targeted therapy to prevent thrombosis and occlusion of the endarterectomized vessels involves the administration of unfractionated heparin in the immediate postoperative period followed by antiplatelet therapy. The rationale of this strategy is not based on any long-term studies, but it could be argued for by the sequential pathologic changes that occur after manual coronary endarterectomy as reported by Walley, Byard, and Keon. ${ }^{22}$ They showed histologic changes over a 7-day period with a mixture of fibrin-platelet deposits on the denuded arterial surface with minimal inflammatory reaction. Therefore, aggressive antiplatelet therapy may prevent inevitable thrombosis, which predisposes the artery to the process of myofibroblast proliferation that will eventually lead to marked narrowing or occlusion. ${ }^{22}$ Despite extensive dissection, aggressive anticoagulation, and antiplatelet therapy, the incidence of re-exploration for bleeding is low.

The limitations of this study include the following: its observational nature, the small sample size, the fact that all patients had a LITA bypass and the same endarterectomy technique regardless of the LAD reconstruction technique, selection bias of the type of reconstruction based on the ease of performing extensive endarterectomy through a single limited arteriotomy vs the necessity to extend the arteriotomy, and finally the lack of other objective criteria of long-term outcomes such as a coronary angiogram and nuclear scans. Many institutions, including ours, do not routinely perform these tests for asymptomatic postoperative patients, particularly in the current era of escalating health care costs and scrutiny. Graft patency rates obtained from symptom-directed studies have been shown to be incorrect. ${ }^{23}$ Reported patency rates for endarterectomized coronary arteries were $90 \%$ to $95 \%$ in the immediate postoperative period, $80 \%$ to $95 \%$ at 1 year, $70 \%$ to $75 \%$ at 3 years, $65 \%$ at 5 years, and $50 \%$ at 10 years. $^{24}$ Finally, the cardioplegia delivery method was not recorded in our data set inasmuch as it was not available in the early study years, and there are no hard data to support our impression of the importance of retrograde cardioplegia. Retrograde blood cardioplegia is now our standard of care in this patient group and has been for the past 10 years.

In conclusion, extensive endarterectomy and reconstruction of the LAD is a safe and feasible technique for complete revascularization of complex, diffuse coronary artery disease. Complete extraction of the atherosclerotic core, careful myocardial protection, and postoperative antithrombotic management are essential for a successful procedure. The reconstruction method did not affect early postoperative outcomes or long-term survival and should be chosen on the basis of conduit availability and the length and location of the arteriotomy.

\section{References}

1. Livesay JJ, Cooley DA, Hallman GL, Reul GJ, Ott DA, Duncan JM, et al. Early and late results of coronary endarterectomy: analysis of 3,369 patients. $J$ Thorac Cardiovasc Surg. 1986;92:649-60.

2. Brenowitz JB, Kayser KL, Johnson WD. Results of coronary artery endarterectomy and reconstruction. J Thorac Cardiovasc Surg. 1988;95:1-10.

3. Christakis GT, Rao V, Fremes SE, Chen E, Naylor CD, Goldman BS. Does coronary endarterectomy adversely affect the results of bypass surgery? J Card Surg. 1993;8:72-8.

4. Djalilian AR, Shumway SF. Adjunctive coronary endarterectomy: improved safety in modern cardiac surgery. Ann Thorac Surg. 1995;60:1749-54.

5. Shapira OM, Akopian G, Hussain A, Adelstein M, Lazar HL, Aldea GS, et al. Improved clinical outcomes in patients undergoing coronary artery bypass grafting with coronary endarterectomy. Ann Thorac Surg. 1999;68:2273-8.

6. Asimakopoulos G, Taylor KM, Ratnatunga CP. Outcome of coronary endarterectomy: a case-control study. Ann Thorac Surg. 1999;67:989-93.

7. Marinelli G, Chiappini B, Di Eusanio M, Di Bartolomeo R, Caldarera I, Marrozzini C, et al. Bypass grafting with coronary endarterectomy: immediate and long-term results. J Thorac Cardiovasc Surg. 2002;124:553-60.

8. Parsonnet V, Gilbert L, Geilchinsky I, Bhaktan EK. Endarterectomy of the left anterior descending and mainstem coronary arteries: a technique for reconstruction of inoperable arteries. Surgery. 1976;80:662-73.

9. Qureshi SA, Halim MA, Pillai R, Smith P, Yacoub MH. Endarterectomy of the left coronary system. J Thorac Cardiovasc Surg. 1985;89:852-9.

10. Gill IS, Beanlands DS, Boyd WD, Finlay S, Keon WJ. Left anterior descending endarterectomy and internal thoracic artery bypass for diffuse coronary disease. Ann Thorac Surg. 1998;65:659-62.

11. Byrne JG, Karavas AN, Gudbjartson T, Leacche M, Rawn JD, Couper GS, et al. Left anterior descending coronary endarterectomy: early and late results in 196 consecutive patients. Ann Thorac Surg. 2004;78:867-74.

12. Shapira N, Lumia FJ, Gottdiener JS, Germon P, Lemole GM. Adjunct endarterectomy of the left anterior descending coronary artery. Ann Thorac Surg. 1988; 46:289-96.

13. Nishi H, Miyamoto S, Takanashi S, Minamimura H, Ishikawa T, Shimizu Y. Optimal method of coronary endarterectomy for diffusely diseased coronary arteries. Ann Thorac Surg. 2005;79:846-53.

14. Beretta L, Lemma M, Vanelli P, DiMattia D, Bozzi G, Broso P, et al. Coronary open endarterectomy and reconstruction: short- and long-term results of the revascularization with saphenous vein versus IMA-graft. Eur J Cardiothorac Surg. 1992;6:382-7.

15. Fundaro P, DiBiasi P, Santoni C. Coronary endarterectomy combined with vein patch reconstruction and internal mammary artery grafting: experience with 18 patients. Texas Heart Inst J. 1987;14:389-94.

16. Ladowski JS, Schatzlein MH, Underhill DJ, Peterson AC. Endarterectomy, vein patch, and mammary bypass of the anterior descending artery. Ann Thorac Surg. 1991;52:1187-9.

17. Aranki SF. A modified reconstruction technique after extended anterior descending artery endarterectomy. J Card Surg. 1993;8:476-82.

18. Tasdemir O, Kiziltepe U, Karagoz HY, Yamak B, Korkmaz S, Bayazit K. Longterm results of reconstructions of the left anterior descending coronary artery in diffuse atherosclerotic lesions. J Thorac Cardiovasc Surg. 1996;112:745-54.

19. Barra JA, Bezon E, Mondine P, Resk A, Gilard M, Mansourati J, et al. Coronary artery reconstruction for extensive coronary disease: 108 patients and two year follow-up. Ann Thorac Surg. 2000;70:1541-5.

20. Shahian DM, O'Brien SM, Filardo G, Ferraris VA, Haan CK, Rich JB, et al. Society of Thoracic Surgeons Quality Measurement Task Force. The Society of Thoracic Surgeons 2008 cardiac surgery risk models: part 1-coronary artery bypass grafting surgery. Ann Thorac Surg. 2009;88(S1):S2-22.

21. Weintraub WS, Clements SD, Crisco LV, Guyton RA, Craver JM, Jones EL, et al. Twenty-year survival after coronary artery surgery: an institutional perspective from Emory University. Circulation. 2003;107:1271-7.

22. Walley VM, Byard RW, Keon WJ. A study of the sequential morphologic changes after manual coronary endarterectomy. J Thorac Cardiovasc Surg. 1991;102:890-4.

23. Buxton BF, Durairaj M, Hare DL, Gordon I, Moten S, Orford V, Seevanayagam S. Do angiographic results from symptom-directed studies reflect true graft patency? Ann Thorac Surg. 2005;80:896-900.

24. Keon WJ, Masters RG, Koshal A, Hendry P, Farell EM. Coronary endarterectomy. An adjunct to coronary artery bypass grafting. Surg Clin North Am. 1988;68:669-78. 